\title{
Mass Media and Self-Esteem, Body Image, and Eating Disorder Tendencies
}

\author{
Jung-Hwan Kim \\ University of South Carolina, Columbia \\ Sharron J. Lennon \\ University of Delaware, Newark
}

\begin{abstract}
This study examines whether the level of exposure to mass media is related to self-esteem, body image, and eating disorder tendencies in a nonexperimental setting based on Festinger's social comparison theory. A convenience sample of 114 female college students participated in this study. Significant positive relationships between exposure to fashion or beauty magazines and (a) overall appearance dissatisfaction and (b) eating disorder tendencies were found. No relationship resulted from television exposure. In addition, risk of eating disorder tendencies was associated with (a) low self-esteem, (b) body dissatisfaction, and (c) overall appearance dissatisfaction.
\end{abstract}

Keywords: body image; eating disorders; mass media; self-esteem; social comparison

$\mathrm{B}$ ody image is the mental image we hold of our bodies (A. Fallon, 1990); it encompasses both how we see ourselves (perceptual) and how we feel about what we see (affective). The topic of body image appears in research literature in a variety of fields such as communication (Botta, 1999; Harrison, 2000), psychology (Cash \& Szymanski, 1995; Cusumano \& Thompson, 1997; Grylli, Hafferl-Gattermayer, Wagner, Schober, \& Karwautz, 2005; Hargreaves \& Tiggemann, 2003), and textiles and clothing (Jung, Lennon, \& Rudd, 2001; Rudd \& Lennon, 2001). An array of measures has been developed to assess body image; for example, J. K. Thompson, Penner, and Altabe (1990) highlighted 38 instruments to assess body image. In addition, many scholarly books (e.g., Cash \& Pruzinsky, 1990, 2002; P. Fallon, Katzman, \& Wooley, 1994; Freedman, 1986, 1988; J. K. Thompson, Heinberg, Altabe, \&
Tantleff-Dunn, 1999) have been written on the topic, attesting to its importance.

Body image develops partly as a function of culture in response to cultural aesthetic ideals (Rudd \& Lennon, 2001). For example, in Westernized societies such as the United States, people tend to perceive thinness and attractiveness as desirable physical traits for women (Silverstein, Perdue, Peterson, \& Kelly, 1986). These perceptions are reinforced via evaluations by and comparisons to others, such as family members, peers, classmates, and media images (J. K. Thompson \& Stice, 2001). Such comparisons are often unconscious. The process of comparison with others is explained by social comparison theory (Festinger, 1954). The theory is based on the idea that people compare their own opinions and abilities to those of others and that the comparison affects self-evaluation (Lee, 1998). For example, comparison to idealized 
images in mass media is instrumental in creating and reinforcing a preoccupation with physical attractiveness (Groesz, Levine, \& Murnen, 2002; Mills, Polivy, Herman, \& Tiggemann, 2002).

The current standard of attractiveness for women portrayed in the media is slimmer than it has been in the past to the point of being unattainable by most women (Hausenblas, Janelle, Gardner, \& Hagan, 2002). Unattainable media images influence women's satisfaction with their bodies (J. K. Thompson \& Stice, 2001) because women compare their bodies with these images (Kenrick \& Gutierres, 1980). Such comparisons may cause depression, anger, body image disturbance (Heinberg \& Thompson, 1995), and low self-esteem (Martin \& Kennedy, 1993). As concerns about body image and eating disorder behaviors among young women have increased in recent years, researchers have begun to examine the thinner standard of beauty portrayed in the media as an influential factor (e.g., Fraze, 2000). The effects of thin images portrayed in media have been investigated in experimental settings. This study extends those results by focusing on investigating relationships among two types of self-reported media exposure and self-esteem, body image, and eating disorder tendencies in a nonexperimental setting. The purpose of this research is, first, to examine relationships of media exposure to (a) self-esteem, (b) body image, and (c) eating disorder tendencies based on Festinger's (1954) social comparison theory and, second, to determine whether both exposure to televised images and to magazine images are similarly related to self-esteem, body image, and eating disorder tendencies.

\section{Review of Literature}

\section{Idealized Images in Mass Media}

People are exposed to innumerable mass media images in the form of billboards, television, and magazines. Although not all advertising images are idealized and some advertising shows relatively ordinary people in everyday situations, most advertising presents an unrealistic or idealized picture of people and their lives (Richins, 1995). The level of beauty and physical attractiveness presented in media images is characteristic of an extremely small segment of the population. Furthermore, the use of technology and special effects allows for images to be yet more perfect and idealized than real life. These unrealistic and idealized images play a significant role in facilitating self-comparisons among women, resulting in an upward shift of individuals' personal image expectations (Blowers, Loxton, Grady-Flesser, Occhipinti, \& Dawe, 2003). In this way, images in the media are problematic for women, especially adolescent and preadolescent women. Viewing thin and beautiful models in advertisements creates self-doubt and dissatisfaction among many young women concerning their bodies and faces and can undermine their self-confidence. As a result, they may indulge in unhealthy eating practices that are associated with eating disorders or turn to invasive procedures such as plastic surgery (Freedman, 1984).

Supporting this idea, the topic of how media exposure negatively affects perceptions of body image and physical attractiveness is prominent in research examining the impact of exposure to attractive models on evaluations of self and others' attractiveness (Groesz et al., 2002). For example, one experiment compared the effects of appearance-related television commercials and non-appearancerelated television commercials on body dissatisfaction among young adolescent girls (Hargreaves \& Tiggemann, 2003). Those exposed to appearance-related commercials became more dissatisfied with their own appearance than those who were exposed to non-appearance-related commercials. Furthermore, Blowers et al. (2003) reported 
that perceived media pressure to be thin was the only significant influence (among family, peers, and media) related to body dissatisfaction via internalization of the thin ideal.

\section{Self-Esteem}

One variable sometimes affected by exposure to media images is self-esteem (Martin \& Kennedy, 1993). Self-esteem is a critical psychological factor that is closely related to mental and/or physical health and social behaviors (Mann, Hosman, Schaalma, \& de Vries, 2004). Rosenberg (1965) defined selfesteem as "a favorable or unfavorable attitude toward the self" (p. 15). Coopersmith (1967) defined self-esteem as either positive or negative self-assessment.

High self-esteem is related to better health, positive social behavior, success, and satisfaction, whereas low self-esteem is associated with risky health behaviors and social problems such as depression, anxiety, eating disorders, and suicidal tendencies (Mann et al., 2004). One of a broad range of critical factors that determine self-esteem is physical attractiveness, an attribute considered particularly important by adolescents. High selfesteem is shown in numerous research studies to protect against body dissatisfaction (e.g., Tiggemann \& Williamson, 2000) and eating disorders (e.g., Geller, Zaitsoff, \& Srikameswaran, 2002). For example, Frost and McKelvie (2004) found a significant relationship between self-esteem and bodycathexis (a measure of body satisfaction) for children, adolescents, and adults. In addition, as compared to women who were satisfied with their body size and shape, female college students who were dissatisfied had lower self-esteem and more eating disorder symptoms (Geller et al., 2002). Therefore, it is reasonable to expect that exposure to thinideal images portrayed in mass media will be associated with negative body attitudes (such as poor body image) and low self-esteem. Accordingly, based on the assumption that higher exposure to mass media leads to greater exposure to idealized images, the first hypothesis was developed:

Hypothesis 1: Among female college students, higher levels of exposure to media (television and fashion or beauty magazines) will be associated with lower levels of self-esteem.

Hypothesis 1a: Higher levels of television exposure will be associated with lower levels of self-esteem.

Hypothesis 1b: Higher levels of fashion or beauty magazine exposure will be associated with lower levels of self-esteem.

\section{Body Image}

Body image is not only the way that people perceive themselves but also how they feel about those perceptions (A. Fallon, 1990). Cash and Pruzinsky (1990) described body image as a complex construct encompassing one's cognitions, emotions, and actions regarding one's body. Body image has been measured in many different ways; one of the simplest ways is assessing the extent to which people are (dis)satisfied with their bodies. Another similar measure taps overall appearance (dis)satisfaction. A highly comprehensive measure is the Multidimensional Body-Self Relations Questionnaire (Brown, Cash, \& Mikulka, 1990; Cash, Winstead, \& Janda, 1986), consisting of several subscales that tap aspects of body image.

Researchers have found strong relationships between body dissatisfaction and (a) depression (Keel, Mitchell, Davis, \& Crow, 2001), (b) mood (Tiggemann \& McGill, 2004), and (c) eating disorder symptomatology (Harrison, 2000; Stice \& Shaw, 1994). According to Stice and Whitenton (2002), almost $25 \%$ of adolescent girls have clinical levels of body dissatisfaction, mainly 
caused by social pressure emanating from family, friends, and media. Stice and Shaw observed that college women who were exposed to attractive images from magazines became less confident, more depressed, more ashamed, and more dissatisfied with their bodies than those who were not exposed to the images. Therefore, college women who are frequently exposed to media images may be less satisfied with their bodies and physical appearance. Based on these arguments, the second testable hypothesis is offered:

Hypothesis 2: Among female college students, higher levels of exposure to media (television and fashion or beauty magazines) will be associated with body image.

Hypothesis 2a: Higher levels of television exposure will be associated with higher levels of body dissatisfaction.

Hypothesis 2b: Higher levels of television exposure will be associated with higher levels of overall appearance dissatisfaction.

Hypothesis 2c: Higher levels of television exposure will be associated with lower levels of appearance evaluation.

Hypothesis 2d: Higher levels of fashion or beauty magazine exposure will be associated with higher levels of body dissatisfaction.

Hypothesis 2e: Higher levels of fashion or beauty magazine exposure will be associated with higher levels of overall appearance dissatisfaction.

Hypothesis 2f: Higher levels of fashion or beauty magazine exposure will be associated with lower levels of appearance evaluation.

\section{Eating Disorders}

The number of research studies focusing on disordered eating behaviors and eatingrelated pathologies has increased dramatically partly because of the emphasis on thinness in Westernized societies (e.g., Grylli et al., 2005; J. K. Thompson \& Stice, 2001).
Two types of eating disorders recognized by the Diagnostic and Statistical Manual of Mental Disorders (4th ed., text revision) (DSM-IV-TR; American Psychiatric Association, 2000) are bulimia nervosa and anorexia nervosa. Bulimia nervosa refers to "recurrent inappropriate compensatory behavior in order to prevent weight gain, such as self-induced vomiting, misuse of laxatives, or excessive exercise" (p. 588), whereas anorexia nervosa is defined as "a refusal to maintain body weight over a minimal normal weight for age and height" (p. 589). Figures for bulimia nervosa and anorexia nervosa among adolescent and college women range from $1.0 \%$ to $2.5 \%$ and $0.2 \%$ to $0.7 \%$, respectively (Karwautz \& Treasure, 2000). The diagnostic criteria for bulimia nervosa and anorexia nervosa, according to the $D S M-I V-T R$, include an intense anxiety about gaining weight and becoming fat and a disturbance of body image. Both disorders are associated with widespread psychopathology that eventually disrupts normal activities at school or work. Among young women, various eating-related problems such as use of laxatives or diuretics, strict eating restraints, and binge eating are associated with body dissatisfaction (Kiemle, Slade, \& Dewey, 1987; Klingenspor, 2002). Furthermore, other research shows that body dissatisfaction is a better predictor of eating disorder behaviors in adolescent women than depression or social anxiety (Gross \& Rosen, 1988). Because exposure to thin-idealized images is considered a crucial factor that exacerbates disordered eating behaviors, the third hypothesis was developed:

Hypothesis 3: Among female college students, higher levels of exposure to media (television and fashion or beauty magazines) will be associated with higher risk of eating disorder tendencies. 
Hypothesis 3a: Higher levels of television exposure will be associated with higher risk of eating disorder tendencies.

Hypothesis 3b: Higher levels of fashion or beauty magazines exposure will be associated with higher risk of eating disorder tendencies.

\section{Body Image, Self-Esteem, and Eating Disorders}

Studies show that most women are likely to perceive themselves as overweight regardless of their actual weight and are more likely to be dissatisfied with their bodies because of distorted perceptions of body size (Birtchnell, Dolan, \& Lacey, 1987). Body size overestimation and body dissatisfaction among women are the best predictors of low selfesteem (Cooper \& Taylor, 1988) and eating disturbances (Cash \& Pruzinsky, 1990). Adolescent women who are more anxious about their physiques are more likely to prefer a smaller body size and weight and have a high risk of developing eating disorder behaviors (A. M. Thompson \& Chad, 2002).

Studies directly examine the relationships between disordered eating behaviors and body image, including satisfaction with body weight and size (e.g., Geller et al., 2002). In essence, people who have eating disorders tend to perceive themselves as unrealistically big or fat and rely on their own perceptions and feelings no matter what feedback they receive about their bodies from others (Rosen, 1990). In addition, they feel that other people evaluate them mainly on their appearance; thus, being thin may be a very important aspect of their selfimage. Accordingly, the following hypotheses were formulated:

Hypothesis 4: Among female college students, there will be a relationship between selfesteem and body image.
Hypothesis 4a: Lower levels of self-esteem will be associated with higher levels of body dissatisfaction.

Hypothesis 4b: Lower levels of self-esteem will be associated with higher levels of overall appearance dissatisfaction.

Hypothesis 4c: Lower levels of self-esteem will be associated with lower levels of appearance evaluation.

Hypothesis 5: Among female college students, lower levels of self-esteem will be associated with higher risk of eating disorder tendencies.

Hypothesis 6: Among female college students, there will be a relationship between body image and risk of eating disorder tendencies.

Hypothesis 6a: Higher levels of body dissatisfaction will be associated with greater risk of eating disorder tendencies.

Hypothesis 6b: Higher levels of appearance dissatisfaction will be associated with greater risk of eating disorder tendencies.

Hypothesis 6c: Lower levels of appearance evaluation will be associated with greater risk of eating disorder tendencies.

\section{Theoretical Framework}

Festinger's (1954) social comparison theory was used as the theoretical framework for this study to address how female college students perceive their self-esteem, body image, and eating disorder tendencies associated with the degree of media exposure. The theory of social comparison is based on the notion that how individuals compare themselves to others affects their self-evaluation (Lee, 1998). People engage in a relatively continuous self-evaluative process to determine whether they are normal. They reflect on their characteristics, strengths, and capabilities to develop a consistent and orderly impression of self and then use this self-examination process to 
facilitate self-understanding and consistent, effective behaviors (J. K. Thompson et al., 1999). However, objective sources of comparison are not always available for self-evaluation, and people examine others as sources of comparison. The process of self-evaluation in comparison with others in the social environment is the basis for Festinger's social comparison theory (J. K. Thompson et al., 1999).

Although originally developed to apply to opinion and ability evaluation, social comparison theory has been applied to studies of the effect of social comparison on selfesteem (e.g., Richins, 1991) and physical appearance (e.g., Heinberg \& Thompson, 1992; Lennon \& Rudd, 1994). Previous research indicates that upward comparisons, comparisons with others who are superior to oneself on the attribute of interest, are often associated with an increase in emotional distress and decrease in self-esteem (Major, Testa, \& Bylsma, 1991). On the other hand, downward comparison may serve as a mechanism of self-enhancement because one may feel better about one's own standing by comparing oneself with someone who is inferior on an attribute of interest (Wood, 1989).

According to Botta (1999), people often automatically compare themselves to others without conscious thought. Because women's images in mass media are extremely thin or slim, automatic social comparisons with these images make women vulnerable to negative feelings (Goethals, 1986). Tiggemann and McGill (2004) showed that women exposed to images of thin-idealized female beauty experienced increased negative moods and body dissatisfaction, and these effects were mediated by the amount of social comparison. In a similar vein, Richins (1991) found that the more women perceived a deficit between idealized advertising images of female models and their own appearance, the more dissatisfied they were with their bodies.
Exposure to idealized images is thought to alter comparison standards of the self, resulting in lower satisfaction (Richins, 1991). According to Botta (1999), this comparison to images and subsequent body dissatisfaction increases the possibility of disordered eating behaviors. Therefore, in this study, social comparison theory is used as a framework to explain the manner in which people compare their bodies to mass media images and how this comparison relates to selfesteem, body image, and eating disorder behaviors. Based on the literature review and conceptual framework, hypothesized models of the relationships among exposure to media (i.e., television and magazines), body image, self-esteem, and eating disorder tendencies were developed (see Figure 1).

\section{Method}

\section{Participants}

The research volunteers were women recruited from an undergraduate textiles and clothing class at a major midwestern university. The course fulfilled a university general education requirement. This study targeted female college students because (a) physical attractiveness is especially important to them (Freedman, 1984), (b) thin and beautiful idealized images in media play a significant role in influencing self-confidence, and (c) these types of images have been associated with eating-related problems (Harrison, 2001; J. K. Thompson \& Stice, 2001).

\section{Pretest}

The questionnaires were pretested by six graduate and undergraduate students from the same participant pool as those in the main study but who were not included in the main study. The pretest was administered to detect any unclear or misunderstood items 
Figure 1

Model of the Relationships Among Exposure to Media, Self-Esteem, Body Image, and Eating Disorder Tendencies

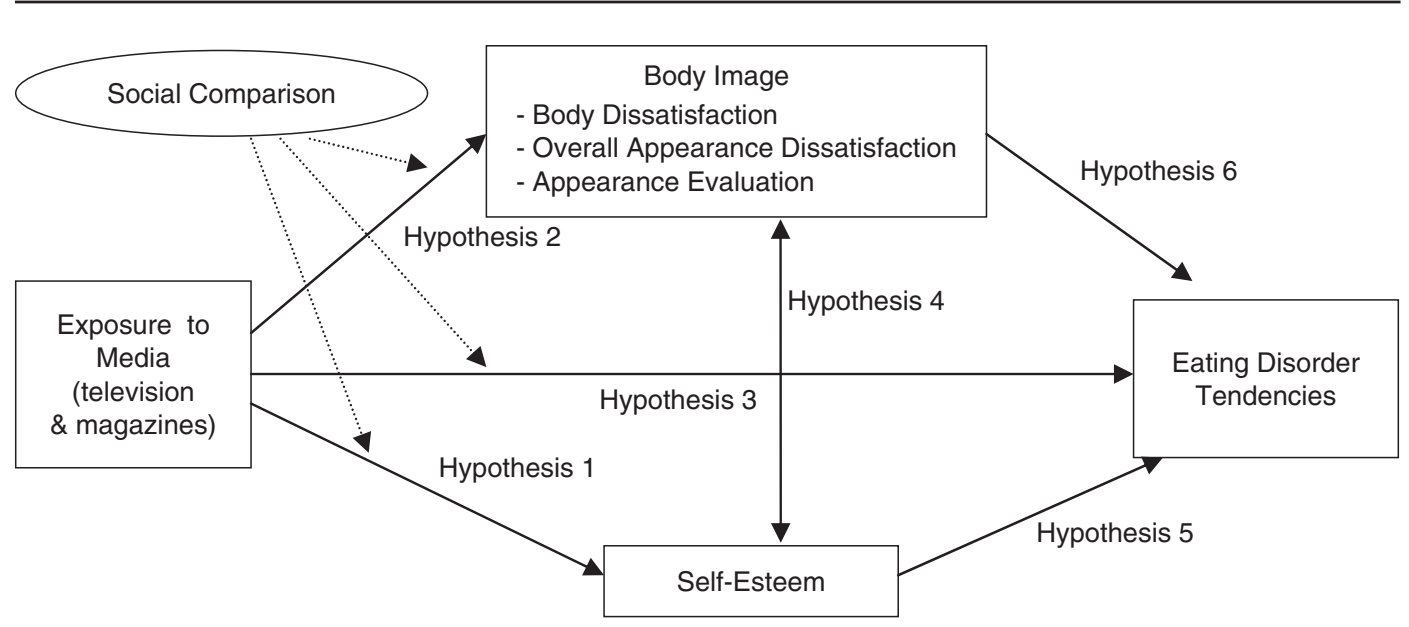

in the questionnaires and to identify any potentially inappropriate questions. Items were found to be clear and understandable.

\section{Instruments}

The principal independent variables in this study were exposure to media (i.e., television and fashion or beauty magazines). Self-esteem and body image (i.e., body dissatisfaction, overall appearance dissatisfaction, and appearance evaluation) were used both as independent variables and dependent variables. Eating disorder tendencies was used as a dependent variable.

Cash and Pruzinsky (2002) defined media exposure as the frequency of magazine reading and hours spent watching television. Using this definition, exposure to television programs was assessed using three 5-point items ( 1 = never, 5 = very often) ("How often have you watched television in the last 3 months?" "How often do you typically watch daytime television?" and "How often do you typically watch television at night?"). Responses to the three television exposure items were summed and mean scores were calculated for data analyses. Higher scores indicate greater exposure to television. Measurement of exposure to fashion or beauty magazines was also based on Cash and Pruzinsky's definition. Two 5point items $(1=$ never, $5=$ very often $)$ were used to assess exposure to fashion or beauty magazines ("How often have you read fashion or beauty magazines in the last 3 months?" and "How often do you purchase fashion or beauty magazines?"). Responses to the two magazine exposure items were summed and mean scores were calculated and entered into data analyses. Higher scores indicate greater exposure to fashion or beauty magazines.

To assess specific information concerning media habits, the names of television programs frequently viewed and magazines frequently read were assessed via two openended items. Respondents were asked to "list television programs that you have frequently watched in the last three months" and to "list names of magazines that you have frequently read in the last three months." The 
open-ended responses were used to identify which television programs and which magazines were the most popular among the participants to get some sense of (a) the extent to which frequently watched television programs were characterized by images portraying thinness and attractiveness and (b) the extent to which the frequently read magazines contained idealized images of thinness and attractiveness.

Demographic information. Participants provided demographic information. Age, height, and weight were assessed using openended formats, and ethnic background was measured using closed-ended response categories.

Self-esteem. Rosenberg's (1965) 10-item Self-Esteem Scale was used to measure selfesteem. An example item is "On the whole, I am satisfied with myself." Items employed a 5-point Likert-type format with endpoints ranging from $1=$ strongly agree to $5=$ strongly disagree. Five of the self-esteem items were reverse scored and then summed and averaged for an overall measure of selfesteem; higher scores indicate a more favorable attitude toward the self. Rosenberg reported test-retest reliabilities ranging from .82 to .88 , and Demo (1985) reported that the scale was a valid measure of self-worth. Previous studies find the scale to have a reproducibility coefficient of .92 (Robinson \& Shaver, 1973) and a scalability of .72 (Kernaleguen \& Conrad, 1981). Rosenberg's measure is the most widely used measure of self-esteem and has good reliability and validity across a wide range of samples (Alfonso, 1995). Also, the measure has been used in other research on body image (e.g., Jung et al., 2001; Lennon \& Rudd, 1994).

Body dissatisfaction and overall appearance dissatisfaction. The Visual Analogue
Scales developed by Heinberg and Thompson (1992) were used in this research to measure two aspects of body image: body dissatisfaction and overall appearance dissatisfaction. The Visual Analogue Scales were developed to measure a state component of body dissatisfaction and has been used in other body image research (e.g., Heinberg \& Thompson, 1995; Jung et al., 2001). Participants indicate their level of dissatisfaction with body and overall appearance by marking on a $100 \mathrm{~mm}$ line anchored by no and extreme. Thus, the measures are 101-point scales with higher scores indicating more dissatisfaction. Jung et al. (2001) reported high reliability $(\alpha=$ .82) for the measures, and Heinberg and Thompson (1995) reported adequate convergent validity for the Visual Analogue Scales.

Appearance evaluation. The Appearance Evaluation subscale of the Multidimensional Body-Self Relations Questionnaire was used to measure other aspects of body image. The questionnaire provides an attitudinal assessment of body image and weightrelated variables and was developed based on national body image survey data (Cash et al., 1986). The Appearance Evaluation subscale is one of the most widely used assessments of the subjective aspect of body image (Brown et al., 1990; Feingold \& Mazzella, 1996). The subscale consists of seven items and has a 5-point Likert-type format with endpoints ranging from $1=$ strongly disagree to $5=$ strongly agree. An example item is "I like my looks just the way they are." The seven items are summed for an appearance evaluation score; higher scores indicate a more positive self-appraisal of appearance. The scale has an internal consistency of .88 and stability of .91 (Cash \& Szymanski, 1995).

Eating disorder tendencies. Garner and Garfinkel's (1979) Eating Attitude Test 
(EAT) was used to measure eating disorder tendencies. The EAT is one of the most widely used self-report instruments that assesses eating disorder tendencies (Mintz \& O'Halloran, 2000). The EAT was originally developed to screen for anorexia nervosa and has proven to be a reliable and valid objective measure of the symptoms of anorexia nervosa (Button \& Whitehouse, 1981; Raciti \& Norcross, 1987). The EAT has been found to be an accurate measure of bulimia and other abnormal eating disorder tendencies as well (Koslowsky et al., 1992; Patton, Johnsone-Sabine, Wood, Mann, \& Wakeling, 1990). Mintz and O'Halloran (2000) found that the EAT has a 90\% accuracy rate in screening people for eating disorders. In a similar manner, Button and Whitehouse (1981) administered the EAT to a large sample of college students and reported that the instrument was useful in identifying eating disorders in nonclinical samples. The EAT has been used in studies of body image (Garner, Garfinkel, Stancer, \& Moldofsky, 1976), body size (Garner \& Garfinkel, 1981), and locus of control (Hood, Moore, \& Garner, 1982). The EAT scale consists of 40 items that use a 5-point Likert-type format $(1=$ very often and $5=$ never). An example item from the EAT scale is "I feel extremely guilty after eating." Item scores on the EAT scale were reverse scored and then summed and averaged for a measure of eating disorder tendencies; higher scores indicate higher levels of eating disorder tendencies or more risk of developing eating disorders. Garner, Olmsted, Bohr, and Garfinkel (1982) reported the intercorrelations among EAT variables as .98, which indicates good reliability.

\section{Procedure}

A questionnaire packet was distributed during class time and returned within the week. Each packet consisted of an informed consent form, a cover letter, a demographic data collection sheet, items measuring media exposure (television programs and magazines), a self-esteem scale, body image scales (i.e., body dissatisfaction, overall appearance dissatisfaction, and appearance evaluation), and a measure of eating disorder tendencies. The importance of participation and the purpose and significance of the research were clearly explained in the cover letter. All participants signed a consent form, which briefly detailed the purpose of the survey.

\section{Results}

\section{Preliminary Analysis}

Sample. Participants were 114 women between the ages of 18 and $27(M=21.5$, $S D=1.83)$. The sample was primarily Caucasian $(79.5 \%)$, with smaller representations from other ethnic groups: about 10\% each for Asian and African American. The self-reported heights of respondents ranged from $4 \mathrm{ft} 11$ in to $5 \mathrm{ft} 9 \mathrm{in}$, with an average of $5 \mathrm{ft} 4 \mathrm{in}$. The range of self-reported weights was $94 \mathrm{lb}$ to $195 \mathrm{lb}$, with an average of $128 \mathrm{lb}$. Based on these values, body mass index was calculated as the ratio of weight to height squared $\left(\mathrm{kg} / \mathrm{m}^{2}\right)$ for each participant. According to the body mass index charts, lower than 20 is categorized as underweight, from 20 to 25 is categorized as normal weight (Garrow, 1986), and higher than 25 is categorized as overweight (Bray, 1986). Body mass index for the respondents ranged from 16.04 to $28.16(M=21.52)$. Nearly $45 \%$ of respondents were categorized normal, about $40 \%$ were categorized underweight, and 14\% were categorized overweight. Therefore, a majority were in the normal and underweight ranges. 
Reliabilities. All reliabilities were assessed using Cronbach's alpha. Reliability for the measure of exposure to television was $\alpha=$ .83 and for the measure of exposure to fashion or beauty magazines was $\alpha=.91$. Reliability for the Self-Esteem Scale was $\alpha=.84$; reliability for the Appearance Evaluation subscale was $\alpha=.86$; and reliability for the EAT was $\alpha=.92$.

Frequently watched television programs. To explore the extent to which respondents were exposed to television programming containing thin-idealized images of women, respondents were asked to list the programs they watched. Respondents provided names of television programs (range $=2$ to 7 ) they had watched frequently during the past 3 months. Frequencies were calculated for the programs named. Of the respondents, $50 \%$ named Friends as the most frequently watched program, 35\% named Will \& Grace, 26\% named American Idol, and 23\% named The Bachelor. Between $10 \%$ and $15 \%$ of the respondents frequently watched Real World, Trading Spaces, Law \& Order, ER, Seinfeld, or CSI (see Table 1). In a study by Harrison (2001), respondents rated television program characters' body sizes using a 7-point rating scale $(1=$ conspicuously fat and $7=$ conspicuously thin). That study finds extremely thin images of women on Friends and moderately thin images of women portrayed on Seinfeld and ER. Thus, at least $50 \%$ of the respondents (those who watched Friends) were exposed to extremely idealized images in television programming.

Frequently read magazines. To access information about media habits, the respondents were asked to indicate names of magazines that they most frequently read (range $=8$ to 0 ; see Table 1). Except for Us Weekly and People, the magazines most frequently read by participants were fashion and beauty magazines (see Table 1). The percentage of participant readership for each magazine was determined. More than $10 \%$ of the respondents read 5 or more of the 10 most frequently read magazines, and $41 \%$ of respondents read 3 or more of the 10 most frequently read magazines (see Table 2).

\section{Testing of Hypotheses}

Hypotheses 1, 2, and 3. A series of multiple regression analyses were used to determine relationships between exposure to media (i.e., television and fashion or beauty magazines) and five dependent variables (i.e., self-esteem, body dissatisfaction, overall appearance dissatisfaction, appearance evaluation, and eating disorder tendencies). Exposure to television and to fashion or beauty magazines were used as independent variables respectively associated with each dependent variable. Results of the analyses revealed that only exposure to fashion or beauty magazines was significantly related to overall appearance dissatisfaction, $F(1,112)=5.6, p<.05, \beta=.22$, and eating disorder tendencies, $F(1,112)=7.2, p<.05, \beta$ $=.25$, and no relationship was found resulting from television exposure. Exposure to fashion or beauty magazines explained $5 \%$ of the variance in overall appearance dissatisfaction, and exposure to fashion or beauty magazines accounted for $6 \%$ of the variance in eating disorder tendencies. Thus, these female college students who were exposed to more fashion or beauty magazines were more dissatisfied with their overall appearance and exhibited a higher risk of eating disorder tendencies. Neither body dissatisfaction nor appearance evaluation was related to either type of media exposure. Therefore, only Hypotheses $2 \mathrm{e}$ and $3 \mathrm{~b}$ were supported by this analysis.

Hypotheses $4 a, 4 b$, and $4 c$. Stepwise multiple regression analysis was used to examine the relationship between body image measures and self-esteem among female college students. Self-esteem scores were used 
Table 1

Frequency of Television Programs and Magazines

\begin{tabular}{lcclcc}
\hline Television Program & Frequency & Percentage & Magazine & Frequency & Percentage \\
\hline Friends & 58 & 49.6 & Cosmopolitan & 67 & 57.3 \\
Will \& Grace & 41 & 35 & In Style & 38 & 32.5 \\
American Idol & 30 & 25.6 & VOGUE & 35 & 29.9 \\
The Bachelor & 27 & 23.1 & Glamour & 32 & 27.4 \\
Real World & 18 & 15.4 & People & 23 & 19.7 \\
Trading Spaces & 15 & 12.8 & Us Weekly & 14 & 12.0 \\
Law \& Order & 14 & 12 & Lucky & 12 & 10.3 \\
ER & 11 & 9.4 & ELLE & 11 & 9.4 \\
Seinfeld & 10 & 8.5 & Marie Claire & 10 & 8.5 \\
CSI & 9 & 7.7 & Harpers Bazaar & 9 & 7.7 \\
\hline
\end{tabular}

Table 2

Exposure to the 10 Most Frequently Read Magazines

\begin{tabular}{lccc}
\hline $\begin{array}{l}\text { Number of Magazines Read } \\
\text { in the Past 3 Months }\end{array}$ & Frequency & Percentage & Cumulative Percentage \\
\hline 8 & 1 & .9 & .9 \\
6 & 2 & 1.7 & 2.6 \\
5 & 9 & 7.7 & 10.3 \\
4 & 8 & 6.8 & 17.1 \\
3 & 27 & 23.1 & 40.2 \\
2 & 29 & 24.8 & 65.0 \\
1 & 21 & 17.1 & 82.1 \\
0 & 21 & 17.9 & 100.0 \\
\hline
\end{tabular}

as the dependent variable and scores on body dissatisfaction, overall appearance dissatisfaction, and appearance evaluation were used as independent variables. Results of the analysis revealed that scores on overall appearance dissatisfaction $(\beta=-.23, t=$ $-2.27, p<.05)$ and appearance evaluation $(\beta=.49, t=4.30, p<.001)$ were significantly related to self-esteem, with $F(2,112)=$ $30.84, p<.001$. The two independent variables explained $36 \%$ of the variance in selfesteem. No relationship between self-esteem and body dissatisfaction was found. This means that these female college students who were dissatisfied with their overall appearance and negatively evaluated their appearance exhibited lower levels of self-esteem.
Therefore, Hypotheses $4 \mathrm{~b}$ and $4 \mathrm{c}$ were supported.

Hypothesis 5. To examine the relationship between scores on self-esteem and scores on eating disorder tendencies among female college students, simple regression analysis was used. Scores on eating disorder tendencies were used as the dependent variable and scores on self-esteem were used as the independent variable. Results of the analysis revealed that self-esteem was related to eating disorder tendencies, with $F(1,112)=31.7, p<.001, \beta=-.47$. Selfesteem accounted for $22 \%$ of the variance in eating disorder tendencies, and the negative beta value indicates the nature of the 
relationship that higher levels of self-esteem are associated with lower levels of eating disorder tendencies. Consequently, Hypothesis 5 was supported.

Hypotheses $6 a, 6 b$, and $6 c$. Stepwise multiple regression analysis was used to examine the relationship among body dissatisfaction, overall appearance dissatisfaction, and appearance evaluation and eating disorder tendencies. Eating disorder tendencies was used as the dependent variable and scores on body dissatisfaction, overall appearance dissatisfaction, and appearance evaluation were used as independent variables. Results of the analysis revealed that scores on body dissatisfaction $(\beta=.30, t=$ $2.47, p<.05)$ and overall appearance dissatisfaction $(\beta=.30, t=2.42, p<.05)$ were significantly related to eating disorder tendencies, with $F(2,112)=26.48, p<.001$. The two independent variables explained $33 \%$ of the variance in eating disorder tendencies. This means that these female college students who were dissatisfied with their bodies and overall appearance exhibited higher levels of eating disorder tendencies. Consequently, Hypotheses 6a and $6 \mathrm{~b}$ were supported.

\section{Discussion}

Out of six hypotheses, five were fully or partially supported. Based on the results of hypothesis testing, it is evident that the relationship of exposure to television on selfesteem (Hypothesis 1a), body image (Hypotheses 2a, 2b, and 2c), and eating disorder tendencies (Hypothesis 3a) was not supported. Thus, the general frequency of television watching did not affect the female college students' self-esteem, body image, and eating disorder tendencies. This lack of support in the study could be explained in several ways. Levels of exposure to television may simply be unrelated to levels of self-esteem, body image, and eating disorder tendencies. Alternatively, although the most frequently watched television programs selected by participants seemed to portray thin-ideal images of women, the images are not portrayed continually and, therefore, may not be intense enough to have a measurable effect.

In previous studies, the effects of television exposure on self-concept or body image were conducted through controlled laboratory investigations (e.g., Heinberg \& Thompson, 1995; Martin \& Kennedy, 1993). For example, Heinberg and Thompson (1995), using a 10-minute presentation of commercials containing women who epitomized societal ideals of thinness and attractiveness, found that media-presented images of thinness and attractiveness negatively affected mood and body satisfaction. However, watching television in natural settings might not have the same effect on female college students' selfesteem, body image, and eating disorders because not all televised images are idealized.

Absence of support for the television exposure hypotheses (Hypotheses 1a, 2a, 2b, 2c, and $3 a$ ) could also be explained in relation to the scales. The measure of exposure to television was related to general frequency of television watching. In other words, no specific exposure to body image-conscious cable channels and programs such as E! TV, MTV, or $\mathrm{HBO}$, which focus on the entertainment industry, was elicited. Therefore, additional research might be designed to elicit information regarding television exposure to programs on those channels. It is possible that exposure to certain channels and programs or duration of exposure is related to self-esteem, body image, and eating disorder tendencies.

In Hypothesis 1b, it was expected that female college students who scored high on the fashion or beauty magazine exposure scale 
would exhibit lower self-esteem scores than those who scored low on the scale. However, no relationship between exposure to fashion or beauty magazines and self-esteem was found. Therefore, Hypothesis $1 \mathrm{~b}$ was not supported, and the results were not consistent with previous research (e.g., Cusumano \& Thompson, 1997; Silverstein et al., 1986). Previous research finds that the relationship was based mainly on the idea that unintended consequences of advertising instill a sense of inadequacy in people (Pollay, 1986), which could eventually undermine the self-worth in women (Freedman, 1984). However, attractive images portrayed in magazines may not be important to self-esteem among collegeage women because self-esteem is established at a young age, and young women may develop self-esteem as a function of other outcomes such as educational success (Mann et al., 2004), school life, and relationships with friends and family rather than idealized images portrayed in magazines.

Respondents in this study were found to have a fairly high level of self-esteem and normal body weights. Therefore, it is not surprising that the unrealistic pictures of models in magazines did not significantly affect most respondents' self-esteem. Henderson-King and Henderson-King (1997) noted that people are not similarly affected by exposure to idealized images because of individual differences and social contextual factors. That is, it is possible that self-esteem is affected by magazine exposure only in women who have high levels of body dissatisfaction or eating disorders. Future research is needed to more thoroughly investigate these relationships.

Based on the review of literature, Hypotheses $2 \mathrm{~d}, 2 \mathrm{e}$, and $2 \mathrm{f}$ presupposed that female college students who scored high on the fashion or beauty magazine exposure scale would be more dissatisfied with their bodies and overall appearance than those who scored low on the scale. The results were not totally consistent with the presupposition. A signifi- cant relationship between exposure to magazines and overall appearance dissatisfaction was found such that greater exposure to fashion or beauty magazines was related to greater overall appearance dissatisfaction. Hence, Hypothesis 2e was supported. According to social comparison theory, people compare themselves to others to evaluate the self. Therefore, the theory of social comparison was confirmed by the positive relation between a high level of exposure to fashion or beauty magazines and overall appearance dissatisfaction. That is, exposure to images portrayed in fashion or beauty magazines may change college women's comparison standards and result in dissatisfaction of their overall appearance. The effects of idealized images on social comparison and body image has been studied in experimental research (e.g., Cash \& Pruzinsky, 2002; Martin \& Kennedy, 1993; Richins, 1991). These studies find that college women compare to models in mass media to evaluate their own physical attractiveness. Therefore, Hypothesis 2e was consistent with other research studies.

Unlike the positive relationship between exposure to fashion or beauty magazines and overall appearance dissatisfaction, no relationship between exposure to fashion or beauty magazines and body dissatisfaction (Hypothesis 2d) or appearance evaluation (Hypothesis 2f) was found. Advertising presents pictures of unrealistically thin, idealized models. In addition, it is well known that technology and special effects such as airbrushing, cropping, and lighting effects are used to make media images appear more perfect or ideal than they are otherwise. Supporting this idea, in an interview with Ms. magazine ("Women of the Year," 2002), Jamie Lee Curtis authorized the magazine to reveal her real body without the use of airbrushing or other photo editing tools to show that the perfect bodies portrayed in magazines are unrealistic and unattainable. In fact, research shows that college students 
recognize bodies depicted in advertisements as unrealistic (Potter, 1986). Thus, participants in our study may have been somewhat skeptical of the bodies portrayed in magazines, and this may have mitigated the undesirable effects of idealized images.

As expected in Hypothesis 3b, the relationship between exposure to fashion or beauty magazines and eating disorder tendencies was statistically significant. Female college students who read more fashion or beauty magazines exhibited a higher risk of eating disorder tendencies. The number of diet articles in women's magazines (Garner \& Garfinkel, 1980) and the frequency of advertising messages promoting slimming products (Toro, Cervera, \& Perez, 1988) focus on slenderness as important to physical attractiveness. Whether or not this idea directly influences female college students' eating disorder tendencies, women do perceive themselves as overweight regardless of actual weight. For example, Gordon (1984) found that $75 \%$ of the female respondents felt fat, whereas according to Metropolitan Life Insurance Tables, only $46 \%$ of them fell into the overweight range. In addition, women who were considerably underweight felt that they were at normal weights (McCauley, Mintz, \& Glenn, 1988). To attain ideal slenderness represented in fashion or beauty magazines, female college students are likely to practice restricted eating. Therefore, the idealized figures of female models in magazines may factor into the development of risky eating behaviors. This is consistent with Botta (1999), who also used social comparison theory and found that media exposure was related to disordered eating tendencies.

In Hypothesis 4, no relationship between self-esteem and body dissatisfaction (Hypothesis 4a) was found. However, there was a negative relationship between selfesteem and overall appearance dissatis- faction (Hypothesis 4b) and a positive relationship between self-esteem and appearance evaluation (Hypothesis 4c). This means that assessment of overall physical appearance and appearance evaluation plays an important role in self-esteem among female college students. This finding is consistent with previous research suggesting that body image has a substantial positive influence on self-esteem (e.g., Cusumano \& Thompson, 1997; Jung et al., 2001; Stice \& Shaw, 1994). Women generally have lower levels of self-esteem than men (Brenner \& Cunningham, 1992), and appearance dissatisfaction has been studied as the main cause (e.g., Mintz \& Betz, 1986). For example, Brenner and Cunningham (1992) found that self-esteem was positively associated with low body weight and body size among women, whereas self-esteem correlated with none of these among men. Such findings suggest that the perception of physical characteristics, including thinness and attractiveness, influences self-esteem of female college students. Therefore, grooming behaviors such as clothing selection and use of facial cosmetics might enhance self-perceived attractiveness and, consequently, selfesteem. The results of Hypotheses $4 \mathrm{~b}$ and $4 \mathrm{c}$ indicate that self-esteem is negatively related to overall appearance dissatisfaction and positively related to appearance evaluation.

As expected in Hypothesis 5, self-esteem was significantly associated with eating disorder tendencies, with lower levels of selfesteem related to higher risk of eating disorder tendencies. People who have eating disorders perceive themselves as unrealistically big or fat and evaluate themselves negatively (Rosen, 1990). Therefore, overall negative self-evaluations led to a higher risk of eating disorders. The Hypothesis 5 result is related to Brenner and Cunningham's (1992) 
study on the relationship between low body weight and higher self-esteem. In that research, the cultural expectation of thinness diminished women's self-esteem, and this led women to engage in consistent risky dieting behaviors to some degree. In fact, women who have pathological eating-related problems tend to have other psychological issues such as depression and social incompetence, along with low self-esteem (Katzman \& Wolchik, 1984). More research on this topic would help aid the development of effective treatment programs dealing with negative self-evaluations associated with body weight and body shape.

In Hypothesis 6, no relationship was found between appearance evaluation and eating disorder tendencies (Hypothesis 6c). However, higher levels of body dissatisfaction (Hypothesis 6a) and overall appearance dissatisfaction (Hypothesis 6b) were significantly related to higher risk of eating disorder tendencies among college women. These results are consistent with previous research on body image (e.g., Cash \& Pruzinsky, 1990), where a significant relationship between body image and eating disorders is shown. That is, the research finds that women who are dissatisfied with their bodies and overall appearance have lower self-esteem, which is related to risky eating behaviors. Physical attractiveness is one of the main concerns of college-age women (Freedman, 1984), and research shows that women tend to compare themselves on the basis of physical appearance (Martin \& Kennedy, 1993; J. K. Thompson \& Heinberg, 1993). Therefore, female college students, who tend to judge others by appearance, recognize that others also judge them on the same basis. When they perceive a major discrepancy between their appearance and what they want to look like, they have a high chance of becoming involved in risky eating behaviors.

\section{Conclusions and Implications}

In this study, exposure to magazines produced more significant results than exposure to television. The content of television programs does not necessarily focus on how women look, unlike the content of fashion or beauty magazines, which were the primary type of magazine chosen by participants. Thus, general television viewing may not significantly affect body image among female college students. Other studies of body image and exposure to television were conducted in experimental settings in which television commercials containing thin-idealized female images (e.g., Hargreaves \& Tiggemann, 2003) caused temporary dissatisfaction with the body. Exposure and effects such as these may have no lasting impact in natural settings. Therefore, research that focuses on the long-term effect of mass media in everyday life is suggested.

A significant relationship between exposure to fashion or beauty magazines and eating disorder tendencies was a crucial result in this study, compared to the findings that (a) exposure to television was unrelated to risky eating behaviors of college women and (b) exposure to fashion or beauty magazines was not related to self-esteem or appearance evaluation. The evidence suggests that continual exposure to thin figures of fashion models in fashion or beauty magazines may make college women unhappy with their body weights and influence their perceptions of themselves as overweight. Therefore, they are likely to engage in dieting behaviors even though the exposure does not cause lower self-esteem or lower appearance evaluation. In this study, social comparison theory partially explains the relationships of exposure to fashion or beauty magazines and overall appearance dissatisfaction and eating disorder tendencies. 
The findings of this study suggest the need to develop additional theoretical and methodological measures to more fully explain all of the media exposure-related relationships.

Much research (e.g., Heinberg \& Thompson, 1995; Stice \& Shaw, 1994) suggests that advertisements that illustrate the ideal female body influence college women to compare themselves and this leads to low self-esteem, body image distortion, negative self-evaluation of physical attractiveness, or eating disorders. Exposure to fashion or beauty magazines (mass media) was found to be a significant influential factor in this study. Furthermore, self-esteem and appearance dissatisfaction were related, as were self-esteem and appearance evaluation, and self-esteem and eating disorder tendencies. The influence of friends, family, or other relatives as a cause of eating disorder tendencies could be studied in future interdisciplinary research with family studies researchers.

The findings of this study suggest that there is a relationship between body image, self-esteem, and eating disorder tendencies among female college students. Levels of self-esteem and body image were found to be positively related, and both were negatively associated with eating disorder tendencies. This is supported by many other studies (e.g., Cusumano \& Thompson, 1997; Silverstein et al., 1986) that find body dissatisfaction is correlated to low self-esteem and high risk of eating disorders. Therefore, a perceived discrepancy in body satisfaction by female college students, when comparing themselves to others or cultural thinness standards, has a significant influence on low self-evaluation and risky eating behaviors. Risky eating behaviors have reached a dangerously high level among college-age women. For example, about $3 \%$ of college women have anorexia nervosa or bulimia nervosa (Karwautz \& Treasure, 2000). We cannot say that all of the activities related to disordered eating have negative consequences, but numerous studies show that lower levels of body weight and body fat cause potentially dangerous illnesses (Valois, Zullig, Huebner, \& Drane, 2003). Therefore, research to examine students' motivations for engaging in risky appearance management behaviors instead of engaging in practices that are more healthful is suggested.

Ideally, external beauty as related to physical appearance attributes such as thinness should not be the measure to evaluate women. Rather, beauty can be perceived as having a healthy balance. A balanced body is different for each person because of personal body structure. With health in mind, each woman can develop her own appropriately balanced body image and may be able to resist being affected by idealized and unrealistic media images and the real or perceived negative opinions of others, thus avoiding the trap of eating disorders. Some apparel advertisers, such as Kmart, have begun to use average or oversize women for their advertisements as well as thin women. The use of realistic models in the media could reduce perceived pressure to be thin and construct positive attitudes of self and, thus, counteract the possible negative influences of idealized media images.

From a social responsibility point of view, the concept of feminine beauty in our society is in need of change. Interior as well as exterior beauty exists in every individual. Parents, teachers, and college counseling services have a responsibility to help female college students develop individuality and value their personal uniqueness. In that sense, investigating how some college women effectively ignore the pressures of societal standards for thinness and physical attractiveness is a possible topic for future research.

Although thinness as a physical attribute is the ideal image for women (Davis, 1985), the middle muscular build is the ideal image for men (Tucker, 1982). Strong men have 
been found to be more satisfied with their body parts, less emotionally unstable, and more confident with themselves than their muscularly weak peers (Tucker, 1983). Therefore, studying the effects of media on male college students is also suggested to determine to what extent male college students are affected by media images and whether they are affected differently than women.

\section{Limitations}

The predominance of one ethnic group and the small range of self-reported body sizes limit generalizability of the results of this study. Almost $80 \%$ of the participants involved in this study were Caucasian Americans, and almost all the participants fell within the normal to underweight range. For this reason, this study cannot be generalized to all college women. The prevalence of overweight and obesity in adults is an increasing health issue (Nicklas, Baranowski, Cullen, \& Berenson, 2001). In the United States, 30\% of adults are overweight and $27 \%$ are obese (Wadden, Brownell, \& Foster, 2002). Therefore, to improve generalizability, a more diverse subject population with a wider variety of ethnicities and body sizes would be useful in exploring the possible influence of media exposure on self-esteem, body image, and eating disorders.

Another limitation of this study is the measure of exposure to television. To measure exposure to television, frequency of general watching of television was assessed. However, not all television programs portray unrealistic and idealized images. General frequency of television watching was not a useful independent variable in this context. Therefore, it is suggested that other measures be used to assess television exposure to idealized images, such as providing a list of specific television programs that portray thin-ideal images.
Finally, the use of the Likert-type frequency scales of media exposure may be a limitation. As with many Likert-type scales, response choices were not specifically defined but left to individual interpretation. Therefore, the perceived exposure to mass media will vary depending on participants' perceptions. Future researchers may wish to specify frequencies (e.g., once a month, once a week, every day).

\section{References}

Alfonso, V. C. (1995). Measures of quality of life, subjective well-being, and satisfaction with life. In D. B. Allison (Ed.), Handbook of assessment methods for eating behaviors and weight-related problems (pp. 23-80). Thousand Oaks, CA: Sage.

American Psychiatric Association. (2000). Diagnostic and statistical manual of mental disorders (4th ed., text revision). Washington, DC: Author.

Birtchnell, S. A., Dolan, B. M., \& Lacey, J. H. (1987). Body image distortion in non-eating disordered women. Journal of Psychosomatic Research, 31, 513-520.

Blowers, L. C., Loxton, N. J., Grady-Flesser, M., Occhipinti, S., \& Dawe, S. (2003). The relationship between sociocultural pressure to be thin and body dissatisfaction in preadolescent girls. Eating Behaviors, 4, 229-244.

Botta, R. A. (1999). Television images and adolescent girls' body image disturbance. Journal of Communication, 49(2), 22-41.

Bray, G. (1986). Effects of obesity on health and happiness. In K. Brownell \& J. Foreyt (Eds.), Handbook of eating disorders: Physiology, psychology, and treatment of obesity, anorexia, and bulimia (pp. 3-44). New York: Basic Books.

Brenner, J. B., \& Cunningham, J. G. (1992). Gender differences in eating attitudes, body concept, and selfesteem among models. Sex Roles, 27(7/8), 413-437.

Brown, T. A., Cash, T. F., \& Mikulka, P. J. (1990). Attitudinal body-image assessment: Factor analysis of the body-self relations questionnaire. Journal of Personality Assessment, 55(1/2), 135-144.

Button, E. J., \& Whitehouse, A. (1981). Subclinical anorexia nervosa. Psychological Medicine, 11, 509-516.

Cash, T. F., \& Pruzinsky, T. (1990). Body images: Development, deviance, and change. New York: Guilford. 
Cash, T. F., \& Pruzinsky, T. (2002). Body image: A handbook of theory, research, and clinical practice. New York: Guilford.

Cash, T. F., \& Szymanski, M. L. (1995). The development and validation of the body image ideals questionnaire. Journal of Personality Assessment, 64(3), 466-477.

Cash, T. F., Winstead, B. A., \& Janda, L. H. (1986). Body image survey report: The great American shape-up. Psychology Today, 24, 30-37.

Cooper, P. J., \& Taylor, M. J. (1988). Body image disturbance in bulimia nervosa. British Journal of Psychiatry, 153(2), 32-36.

Coopersmith, S. (1967). The antecedents of selfesteem. San Francisco: Freeman.

Cusumano, D. L., \& Thompson, J. K. (1997). Body image and body shape ideals in magazines: Exposure, awareness, and internalization. Sex Roles, 37(9/10), 701-721.

Davis, L. L. (1985). Perceived somatotype, bodycathexis, and attitudes toward clothing among college females. Perceptual and Motor Skills, 61, 1199-1205.

Demo, D. H. (1985). The measurement of self-esteem: Refining our methods. Journal of Personality and Social Psychology, 48, 1490-1502.

Fallon, A. (1990). Culture in the mirror: Sociocultural determinants of body image. In T. F. Cash \& T. Pruzinsky (Eds.), Body images: Development, deviance, and change (pp. 80-109). New York: Guilford.

Fallon, P., Katzman, M., \& Wooley, S. (Eds.). (1994). Feminist perspectives on eating disorders. New York: Guilford.

Feingold, A., \& Mazzella, R. (1996). Gender differences in body image are increasing. Gender Psychologist, 32, 90-98.

Festinger, L. (1954). A theory of social comparison processes. Human Relations, 7, 117-140.

Fraze, J. L. (2000). Women's perspectives on the thin ideal in the development of eating disorders (Doctoral dissertation, University of Georgia, 2001). Dissertation Abstracts International, 61(8), 3073A.

Freedman, R. J. (1984, Summer/Fall). Reflections on beauty as it relates to health and adolescent females. Women and Health, 9, 29-45.

Freedman, R. J. (1986). Beauty bound. Lexington, MA: Lexington Books.

Freedman, R. J. (1988). Bodylove. New York: Harper \& Row.

Frost, J., \& McKelvie, S. (2004). Self-esteem and body satisfaction in male and female elementary school, high school, and university students. Sex Roles, 51(1/2), 45-54.

Garner, D. M., \& Garfinkel, P. E. (1979). The Eating Attitude Test: An index of the symptoms of anorexia nervosa. Psychological Medicine, 9, 273-279.

Garner, D. M., \& Garfinkel, P. E. (1980). Socio-cultural factors in the development of anorexia nervosa. Psychological Medicine, 10, 647-656.

Garner, D. M., \& Garfinkel, P. E. (1981). Body image in anorexia nervosa: Measurement, theory, and clinical implications. International Journal of Psychiatry in Medicine, 11, 263-284.

Garner, D. M., Garfinkel, P. E., Stancer, H. C., \& Moldofsky, H. (1976). Body image disturbances in anorexia nervosa and obesity. Psychosomatic Medicine, 38, 227-237.

Garner, D. M., Olmsted, M. P., Bohr, Y., \& Garfinkel, P. E. (1982). The Eating Attitude Test: Psychometric features and clinical correlates. Psychological Medicine, 12, 871-878.

Garrow, J. S. (1986). Physiological aspects of obesity. In K. Brownell \& J. Foreyt (Eds.), Handbook of eating disorders: Physiology, psychology, and treatment of obesity, anorexia, and bulimia (pp. 45-62). New York: Basic Books.

Geller, J., Zaitsoff, S. L., \& Srikameswaran, S. (2002). Beyond shape and weight: Exploring the relationship between nonbody determinants of self-esteem and eating disorder symptoms in adolescent females. International Journal of Eating Disorders, 32(3), 344-351.

Goethals, G. R. (1986). Social comparison theory: Psychology from the lost and found. Personality and Social Psychology Bulletin, 12(3), 261-278.

Gordon, L. (1984, February). Feeling fat in a thin society. Glamour, pp. 198-201, 251-252.

Groesz, L. M., Levine, M. P., \& Murnen, S. K. (2002). The effect of experimental presentation of thin media images on body satisfaction: A meta-analytic review. International Journal of Eating Disorders, 31(1), 1-16.

Gross, J., \& Rosen, J. C. (1988). Bulimia in adolescents: Prevalence and psychosocial correlates. International Journal of Eating Disorders, 7(1), 51-61.

Grylli, V., Hafferl-Gattermayer, A., Wagner, G., Schober, E., \& Karwautz, A. (2005). Eating disorders and eating problems among adolescents with type 1 diabetes: Exploring relationships with temperament and character. Journal of Pediatric Psychology, 30(2), 197-206. 
Hargreaves, D., \& Tiggemann, M. (2003). The effect of thin ideal television commercials on body dissatisfaction and schema activation during early adolescence. Journal of Youth and Adolescence, 32(5), 367-373.

Harrison, K. (2000). Television viewing, fat stereotyping, body shape standards, and eating disorder symptomatology in grade school children. Соттиnication Research, 27, 617-640.

Harrison, K. (2001). Ourselves, our bodies: Thinideal media, self-discrepancies, and eating disorder symptomatology in adolescents. Journal of Social and Clinical Psychology, 20(3), 289-323.

Hausenblas, H. A., Janelle, C. M., Gardner, R. E., \& Hagan, A. L. (2002). Effects of exposure to physique slides on the emotional responses of men and women. Sex Roles, 47(11/12), 569-575.

Heinberg, L. J., \& Thompson, J. K. (1992). The effects of figure size feedback (positive vs. negative) and target comparison group (particularistic vs. universalistic) on body image disturbance. International Journal of Eating Disorders, 12, 441-448.

Heinberg, L. J., \& Thompson, J. K. (1995). Body image and televised images of thinness and attractiveness: A controlled laboratory investigation. Journal of Social and Clinical Psychology, 17, 1-14.

Henderson-King, E., \& Henderson-King, D. (1997). Media effects on women's body esteem: Social and individual difference factors. Journal of Applied Social Psychology, 27, 399-417.

Hood, J., Moore, T. E., \& Garner, D. M. (1982). Locus of control as a measure of ineffectiveness in anorexia nervosa. Journal of Consulting and Clinical Psychology, 50, 3-13.

Jung, J., Lennon, S. J., \& Rudd, N. A. (2001). Selfschema or self-discrepancy? Which best explains body image? Clothing and Textiles Research Journal, 19(4), 171-184.

Karwautz, A., \& Treasure, J. (2000). Eating disorders. In P. Aggleton, J. Hurry, \& I. Warwick (Eds.), Young people and mental health (pp.73-90). New York: John Wiley.

Katzman, M. A., \& Wolchik, S. A. (1984). Bulimia and binge eating in college women: A comparison of personality and behavioral characteristics. Journal of Consulting and Clinical Psychology, 52(3), 423-428.

Keel, P. K., Mitchell, J. E., Davis, T. L., \& Crow, S. J. (2001). Relationship between depression and body dissatisfaction in women diagnosed with bulimia nervosa. International Journal of Eating Disorders, 30(1), 48-56.
Kenrick, D. T., \& Gutierres, S. E. (1980). Contrast effects and judgments of physical attractiveness: When beauty becomes a social problem. Journal of Personality and Social Psychology, 38, 131-140.

Kernaleguen, A., \& Conrad, G. (1981). Analysis of five measures of self-concept. Perceptual and Motor Skills, 51, 855-861.

Kiemle, G., Slade, P. D., \& Dewey, M. E. (1987). Factors associated with abnormal eating attitudes and behaviors: Screening individuals at risk of developing an eating disorder. International Journal of Eating Disorders, 6, 713-724.

Klingenspor, B. (2002). Gender-related self-discrepancies and bulimic eating behavior. Sex Roles, 47(1/2), 51-64.

Koslowsky, M., Scheinberg, Z., Bleich, A., Mark, M., Apter, A., Danon, Y., et al. (1992). The factor structure and criterion validity of the short form of the Eating Attitude Test. Journal of Personality Assessment, 58, 27-35.

Lee, S. (1998). Body image, self-esteem, and compulsive shopping behavior among television shoppers. Unpublished doctoral dissertation, The Ohio State University, Columbus.

Lennon, S. J., \& Rudd, N. A. (1994). Linkages between attitudes toward gender roles, body satisfaction, self-esteem, and appearance management behaviors in women. Family and Consumer Sciences Research Journal, 23, 94-117.

Major, B., Testa, M., \& Bylsma, W. H. (1991). Responses to upward and downward social comparisons: The impact of esteem-relevance and perceived control. In J. Suls \& T. A. Wills (Eds.), Social comparison: Contemporary theory and research (pp. 237-260). Hillsdale, NJ: Lawrence Erlbaum.

Mann, M., Hosman, C. M. H., Schaalma, H. P., \& de Vries, N. K. (2004). Self-esteem in a broad-spectrum approach for mental health promotion. Health Education Research, 19(4), 357-372.

Martin, M. C., \& Kennedy, P. F. (1993, November/ December). Advertising and social comparison: Consequences for female preadolescents and adolescents. Psychology \& Marketing, 10(6), 513-530.

McCauley, M. L., Mintz, L., \& Glenn, A. A. (1988). Body-image, self-esteem, and depression-proneness: Closing the gender gap. Sex Roles, 18, 381-391.

Mills, J. S., Polivy, J., Herman, C. P., \& Tiggemann, M. (2002). Effects of exposure to thin media images: Evidence of self-enhancement among restrained eaters. Personality and Social Psychology Bulletin, 28(12), 1687-1699. 
Mintz, L. B., \& Betz, N. B. (1986). Sex differences in the nature, realism, and correlates of body image. Sex Roles, 15, 185-195.

Mintz, L. B., \& O'Halloran, M. S. (2000). The Eating Attitudes Test: Validation with DSM-IV eating disorder criteria. Journal of Personality Assessment, 74(3), 489-503.

Nicklas, T. A., Baranowski, T., Cullen, K. W., \& Berenson, G. (2001). Eating patterns, dietary quality and obesity. Journal of the American College of Nutrition, 20(6), 599-608.

Patton, G. C., Johnsone-Sabine, E., Wood, K., Mann, A. H., \& Wakeling, A. (1990). Abnormal eating attitudes in London schoolgirls-A prospective epidemiological study: Outcome at twelve month follow-up. Psychology Medicine, 20, 383-394.

Pollay, R. W. (1986, April). The distorted mirror: Reflections on the unintended consequences of advertising. Journal of Marketing, 50, 18-36.

Potter, W. J. (1986, Spring). Perceived reality and the cultivation hypothesis. Journal of Broadcasting and Electronic Media, 30, 159-174.

Raciti, M. C., \& Norcross, J. C. (1987). The EAT and EDI: Screening, interrelationships, and psychometrics. International Journal of Eating Disorders, 6, 579-586.

Richins, M. L. (1991). Social comparison and the idealized images of advertising. Journal of Consumer Research, 18, 71-83.

Richins, M. L. (1995, February). Social comparisons, advertising, and consumer discontent. American Behavioral Scientist, 38(4), 593-607.

Robinson, J. P., \& Shaver, P. R. (1973). Measures of social psychological attitudes. Ann Arbor, MI: Institute for Social Research. Survey Research Center.

Rosen, J. C. (1990). Body image disturbances in eating disorders. In T. F. Cash \& T. Pruzinsky (Eds.), Body images: Development, deviance, and change (pp. 190-214). New York: Guilford.

Rosenberg, M. (1965). Society and the adolescent self-image. Princeton, NJ: Princeton University Press.

Rudd, N. A., \& Lennon, S. J. (2001). Body image: Linking aesthetics and social psychology of appearance. Clothing and Textiles Research Journal, 19(3), 120-133.

Silverstein, B., Perdue, L., Peterson, B., \& Kelly, E. (1986). The role of the mass media in promoting a thin standard of bodily attractiveness for women. Sex Roles, 14(9/10), 519-532.

Stice, E., \& Shaw, H. E. (1994). Adverse effects of the media portrayed thin-ideal on women and linkages to bulimic symptomatology. Journal of Social and Clinical Psychology, 13, 288-308.

Stice, E., \& Whitenton, K. (2002). Risk factors for body dissatisfaction in adolescent girls: A longitudinal investigation. Developmental Psychology, 38(5), 669-678.

Thompson, A. M., \& Chad, K. E. (2002). The relationship of social physique anxiety to risk for developing an eating disorder in young females. Journal of Adolescent Health, 31(2), 183-189.

Thompson, J. K., \& Heinberg, L. J. (1993). A preliminary test of two hypotheses of body image disturbance. International Journal of Eating Disorders, 14, 59-64.

Thompson, J. K., Heinberg, L. J., Altabe, M., \& Tantleff-Dunn, S. (1999). Future directions: Integrative theories, multidimensional assessments, and multicomponent interventions. In J. K. Thompson \& L. J. Heinberg (Eds.), Exacting beauty: Theory, assessment, and treatment of body image disturbance (pp. 311-332). Washington, DC: American Psychological Association.

Thompson, J. K., Penner, L. A., \& Altabe, M. N. (1990). Procedures, problems, and progress in the assessment of body images. In T. F. Cash \& T. Pruzinsky (Eds.), Body images: Development, deviance, and change (pp. 21-48). New York: Guilford.

Thompson, J. K., \& Stice, E. (2001). Thin-ideal internalization: Mounting evidence for a new risk factor for body image disturbance and eating pathology. Current Directions in Psychological Science, 10, 181-183.

Tiggemann, M., \& McGill, B. (2004). The role of social comparison in the effect of magazine advertisements on women's mood and body dissatisfaction. Journal of Social and Clinical Psychology, 23(1), 23-44.

Tiggemann, M., \& Williamson, S. (2000). The effect of exercise on body satisfaction and self-esteem as a function of gender and age. Sex Roles, 43(1/2), 119-127.

Toro, J., Cervera, M., \& Perez, P. (1988). Body shape, publicity and anorexia nervosa. Social Psychiatry and Psychiatric Epidemiology, 23, 132-136.

Tucker, L. A. (1982). Relationship between perceived somatotype and body cathexis of college males. Psychological Reports, 50, 983-989.

Tucker, L. A. (1983). The structure and dimensional satisfaction of the body cathexis construct of males: A factor analytic investigation. Journal of Movement Studies, 9, 189-194.

Valois, R. F., Zullig, K. J., Huebner, E. S., \& Drane, J. W. (2003). Dieting behaviors, weight perceptions, 
and life satisfaction among public high school adolescents. Eating Disorders: The Journal of Treatment \& Prevention, 11(4), 271-288.

Wadden, T. A., Brownell, K. D., \& Foster, G. D. (2002). Obesity: Responding to the global epidemic. Journal of Consulting \& Clinical Psychology, 70(3), 510-525.

Women of the year. (2002). Ms. Retrieved May 21, 2003, from http://www.msmagazine.com/dec02/ womenoftheyear.asp

Wood, J. V. (1989). Theory and research concerning social comparisons of personal attributes. Psychological Bulletin, 106, 231-248.

Jung-Hwan Kim is an assistant professor in the Department of Retailing at University of South Carolina. She received her PhD from The Ohio State
University. Her research interests include consumer shopping behaviors, multichannel retailing, and social responsibility associated with body image.

Sharron J. Lennon is the Irma Ayers Professor in the Department of Fashion and Apparel Studies at the University of Delaware. She received her $\mathrm{PhD}$ from Purdue University and has published more than 90 research articles and book chapters. Her research interests include online visual merchandising, online shopping, extreme consumption, consumption of fashion counterfeit products, and customer service in the multichannel context. 